\title{
State Preparedness for Crisis Standards of Care in the United States: Implications for Emergency Management
}

\author{
Annie E. Ingram, BA; ${ }^{1}$ (i) Attila J. Hertelendy, PhD; ${ }^{1,2,3,4}$ Michael S. Molloy, MB, MCh, EMDM, \\ FRCEM, FRCSEd FFSEM; ${ }^{3,5,6}$ (ㅇ) Gregory R. Ciottone, MD, FACEP, FFSEM ${ }^{3,4}$
}

1. Disaster and Emergency Management Program, School of Continuing Studies, Georgetown University, Washington, DC USA

2. Department of Information Systems and Business Analytics, College of Business, Florida International University, Miami, Florida USA

3. Fellowship in Disaster Medicine, Department of Emergency Medicine, Beth Israel Deaconess Medical Center, Boston, Massachusetts USA

4. Department of Emergency Medicine, Harvard Medical School, Boston, Massachusetts USA

5. Department of Emergency Medicine, Wexford General Hospital, Wexford, Ireland

6. School of Medicine, University College Dublin, Dublin, Ireland

Correspondence:

Annie E. Ingram, BA

Georgetown University

School of Continuing Studies

640 Massachusetts Ave NW

Washington, DC 20001 USA

E-mail: aes365@georgetown.edu

Conflicts of interest: none

Keywords: crisis standards of care; emergency management; moral distress; pandemic

Abbreviations:

COVID-19: novel coronavirus disease 2019

CSC: crisis standards of care

IOM: Institute of Medicine

NAS: National Academy of Sciences

PAHPA: Pandemic and All-Hazards Preparedness

and Advancing Innovation Act

Received: September 24, 2020

Accepted: October 22, 2020

\section{Abstract}

State governments and hospital facilities are often unprepared to handle a complex medical crisis, despite a moral and ethical obligation to be prepared for disaster. The 2019 novel coronavirus disease (COVID-19) has drawn attention to the lack of state guidance on how hospitals should provide care in a crisis. When the resources available are insufficient to treat the current patient load, crisis standards of care (CSC) are implemented to provide care to the population in an ethical manner, while maintaining an ability to handle the surge. This Editorial aims to raise awareness concerning a lack of preparedness that calls for immediate correction at the state and local level.

Analysis of state guidelines for implementation of CSC demonstrates a lack of preparedness, as only five states in the US have appropriately completed necessary plans, despite a clear understanding of the danger. States have a legal responsibility to regulate the medical care within their borders. Failure of hospital facilities to properly prepare for disasters is not a new issue; Hurricane Katrina (2005) demonstrated a lack of planning and coordination. Improving disaster health care readiness in the United States requires states to create new policy and legislative directives for the health care facilities within their respective jurisdictions. Hospitals should have clear directives to prepare for disasters as part of a "duty to care" and to ensure that the necessary planning and supplies are available to their employees.

Ingram AE, Hertelendy AJ, Molloy MS, Ciottone GR. State preparedness for crisis standards of care in the United States: implications for emergency management. Prehosp Disaster Med. 2021;36(1):1-3.

\section{Introduction}

Crisis standards of care (CSC) are the methods by which the needs of the population are placed above those of the individual patient, ethically and safely, when resources are inadequate for the current operating environment. ${ }^{1}$ Implementing CSC requires significant planning and individuals capable of making complex decisions, in pressurized environments, with information deficits. ${ }^{1,2}$ Situations where CSC plans are implemented require critical thinking and trained individuals to avoid discrimination and unethical use of resources. ${ }^{1,2}$ Terminology for CSC has only been widely discussed for the past two decades, with some policies still in development. ${ }^{3}$ While CSC is a topic that can be emotional for many and easily misunderstood, every hospital and jurisdiction needs to be prepared for the situations which may require implementation of these very standards. Very few states in the US

\section{doi:10.1017/S1049023X20001405}

(C) The Author(s), 2020. Published by Cambridge University Press on behalf of World Association for Disaster and Emergency Medicine 2020. This is an Open Access article, distributed under the terms of the Creative Commons Attribution-NonCommercial-ShareAlike licence (http://creativecommons. org/licenses/by-nc-sa/4.0/), which permits non-commercial re-use, distribution, and reproduction in any medium, provided the same Creative Commons licence is included and the original work is properly cited. The written permission of Cambridge University Press must be obtained for commercial re-use. 
Preparedness for Crisis Standards of Care

have comprehensive plans that meet industry standards, which has left local providers without guidance. ${ }^{4}$ The following will be an indepth review of current recommendations and state guidelines for $\mathrm{CSC}$, as well as proposed changes based on lessons-learned industry best practices and innovative public health emergency management policies.

\section{Literature Review}

There are several publications available from the National Academy of Sciences (NAS; Washington, DC USA), the American Journal of Public Health (AJPH; American Public Health Association; Washington, DC USA), and the National Institute for Sciences (NIS; Washington, DC USA), with additional articles and procedural recommendations published in 2020 due to the novel coronavirus disease 2019 (COVID-19) and the increased need for CSC implementation across the globe. Crisis Standards of Care: Ten Years of Successes and Challenges: Proceedings of a Workshop was published in 2020 by NAS following a two-day workshop held in November of 2019. ${ }^{3}$ The workshop's goal was to explore changes and ethics in CSC and the effectiveness of $\mathrm{CSC}$ implementation over the previous ten years, as well as to consider priorities for the next decade. ${ }^{3}$ The workshop highlighted the importance of the following key issues surrounding CSC: waiting to implement $\mathrm{CSC}$ until the state has made the disaster declaration for the sake of legal protections, national standardization of CSC, and the political implications of shifting the environment from "first come, first served" to that of "placing the population first." 3

The workshop built upon the previously published Crisis Standards of Care: A Toolkit for Indicators and Triggers. ${ }^{1}$ This toolkit introduced a five-pillar framework detailing roles and responsibilities for emergency management, hospitals, emergency services, and public health. ${ }^{1}$ The toolkit highlights emergency management's importance as the coordinators for disasters, providing a connection between essential functions, the incident response, and health care infrastructure. ${ }^{1}$

The ethics of CSC are complex and require extensive consideration, training, and piloting prior to successful implementation. For example, during the 2020 COVID-19 pandemic, ventilators became a scarce resource. The allocation and duration of use of ventilators is now a hotly disputed topic..$^{5}$ Since 2012 , one of the more significant concerns is the ethical justification of CSC and the criteria used in decision making for resource distribution. ${ }^{6}$ Leider and colleagues compiled a systematic review of more than 300 articles assessing the impact of NAS's previous publications on CSC. ${ }^{6}$ The most frequently discussed topics were ethical standards criteria and the duty to care. ${ }^{6}$ Additional issues of relevance in relation to CSC included the mental health impacts of implementing CSC, equality, and rationing. ${ }^{2,6}$

The argument against CSC is primarily that its implementation reduces "the legal standard or duty of care" for medical responders. It is argued that: "the effort to create altered care standards is unnecessary and divisionary," further that liability claims aren't filed against physicians during disasters, and finally that changing the standards of care would prevent the improvement of disaster and emergency management. ${ }^{7}$ Despite the controversies surrounding CSC, the District of Columbia and 41 states in the US have published documents related to $\mathrm{CSC}^{4}$ Of these, 11 were not CSC plans, and of the 31 remaining guidelines, only five contained the elements recommended by the National Academy of Medicine (formerly Institute of Medicine [IOM]; Washington, DC USA) in 2009. ${ }^{4}$ Minnesota's plan, last updated in 2010, includes a detailed ethical rationale for their recommendations. ${ }^{4}$ Arizona's plan utilizes ethics as a foundation and places compassion as a primary focus of the plan. ${ }^{4,8}$ The review goes on to evaluate the different state's communication, engagement, education, legal considerations, and applicability planning. ${ }^{4}$ This review demonstrates a lack of preparedness for CSC implementation nation-wide, as less than $10 \%$ of the states have comprehensive plans that meet the standards laid out by IOM over a decade previously, which were published during the $\mathrm{H} 1 \mathrm{~N} 1$ pandemic. $^{4}$

\section{Implications for Emergency Management}

Departments of emergency management serve as the lead agency for coordination during a disaster, with their primary responsibilities being: incident management and incident action plans, public information and risk communications, maintaining situational awareness, resource management and logistics, transportation, communications, mass care and sheltering, public works, and legal regulations surrounding disasters. ${ }^{1}$ The IOM CSC toolkit highlights the importance of emergency management having an active role in planning and coordination with the health care system and public health. ${ }^{1} \mathrm{~A}$ communicative and well-functioning relationship between emergency management and public health is vital for a synergistic disaster response. ${ }^{1}$

The lack of active participation by emergency management agencies will negatively impact the overall response. ${ }^{1} \mathrm{~A}$ review of the current status of individual state $\mathrm{CSC}$ plans revealed the majority of states in the US do not maintain CSC plans. ${ }^{9}$ Several states only published a CSC plan in 2020, while some have COVID-19specific policies or have incomplete plans primarily focused on triage or the medical management of patients that relate to CSC. ${ }^{8,9}$ Educational organizations, as in Florida, published CSC plans; while others were published by health organizations, as in Illinois. ${ }^{9}$ A review of state plans published in early 2020 found that only five states had plans that included all five pillars outlined by the IOM, with 18 out of the 31 plans available for review having a strong ethical grounding. ${ }^{4}$ Arizona, Colorado, Minnesota, Nevada, and Vermont are the five states that currently have publicly available comprehensive plans meeting the standards laid out by the IOM, with Vermont's plan still in draft form. ${ }^{4}$

The first paragraph of Connecticut's CSC plan directly addressed the issues that are present in COVID-19, a decade before the virus presented itself:

Many experts predict that the next emergency will be a prolonged public health emergency. Indeed, most experts say that it is not a question of "if," but "when." During such an event, health care facilities will face "the perfect storm" of an overwhelming demand for services accompanied by a critical shortage of resources that will profoundly challenge the underpinnings of our health care system and the individuals who comprise it. The success with which health care facilities and providers meet these challenges will be directly related to how well they plan and prepare for such an event. ${ }^{10}$

This quote directly demonstrates the failure of the public health, health care, and emergency management fields to address widely known deficiencies within the industry. In the COVID-19 pandemic, the US was unprepared for handling patient surge with inadequate levels of resources, as demonstrated by only five states having pre-developed and published comprehensive CSC. ${ }^{4}$

The term CSC has only existed for the past two decades; the primary issue has, however, existed for quite some time. ${ }^{3}$ Hurricane Katrina (2005) brought the issue of health care disaster planning to the forefront through a national scandal focused on New Orleans. ${ }^{11}$ In 2005, 45 people were found dead at Memorial 
Hospital and another 19 at Lindy Boggs Medical Center, due in large part to the failure of generators, slow and disorganized rescue operations, and poor communications. ${ }^{11}$ One of the significant lessons learned was the lack of preparedness, planning, and coordination between hospitals and the local and state governments. ${ }^{11}$ While the COVID-19 pandemic is not the same as a hurricane, it is a hazard that public health, emergency management, and health care organizations should have prepared for in advance of the virus' arrival in the US in early January 2020.

\section{Recommendations}

Very few states in the US have adequate CSC plans; a lack of planning results in an uncoordinated response and leaves health care and public health officials scrambling to create a workable plan with very little time. ${ }^{8}$ Research completed in 2015 accurately predicted the shortage of ventilators witnessed during the COVID-19 pandemic and highlighted the need for better resource management planning. ${ }^{12}$ Just as Connecticut's CSC plan states, public health emergencies "are not a question of if, but when. Emergencies that require the implementation of CSC plans are going to happen, the only question is the timing of such events." ${ }^{\text {"O }}$ Comprehensive CSC plans should be implemented any time crisis operations overwhelm a hospital's resources, and are not limited only to pandemic response.

According to the Pandemic and All-Hazards Preparedness and Advancing Innovation Act of 2019 (PAHPA), SEC. 319C-3 directs various federal agencies to develop all-hazard guidelines for health care system-wide public health emergency preparedness to ensure adequate patient care before, during, and after a public health emergency. ${ }^{13}$ This directive includes the management of emerging infectious diseases, resources, and the education of responsible partners of the region in medical emergency management practices. ${ }^{13}$ The guidance outlined in the PAHPA is to be published by 2021 and should include recommendations for all states to maintain and regularly update CSC plans. ${ }^{13}$ However, it is not enough for just the states to prepare for CSC plan implementation; all hospitals in the US should also have robust all-hazards CSC plans. ${ }^{14}$

Regulatory and ethical considerations that make up the foundation of CSC plans should be augmented by legal statues that cement a "duty to plan," or a legal obligation for health care facilities to be prepared. ${ }^{15}$ Social contract theory indicates that people have fundamental rights that exist outside of government, and the justification for government is that it exists to improve the quality of life. ${ }^{16}$ The improvement of life as a fundamental part of government existence as a part of social contract theory requires that government be prepared and plan for events the public is not capable of managing independently. ${ }^{16}$ While hospitals have been required to prepare for disasters in the past, a standard of what that preparedness level should be has not been clearly determined and should be the focus of future research. ${ }^{17} \mathrm{It}$ is important for future policies and regulations at all levels of government to provide clear ethical and legal requirements for health care facilities so they can be better prepared for the demands of a health care crisis.

\section{Conclusions}

The lack of preparedness in the health care system for the demands of patient care in a crisis is indisputable, particularly considering the COVID-19 response. Individual states in the US are responsible for the management of public health within their borders, and highlighting their responsibility will help to improve readiness overtime. Introducing new legislation and policy that outlines a clear and concise level of preparedness is vital for efficient and ethical crisis response in the health care community. While health care providers are required by oath to care for patients in need, health care organizations should be held to an even higher standard of disaster preparedness, so that in the event of a crisis, doctors and nurses are capable of fulfilling that oath. An evidence-based health care standard of preparedness should be the focus of further research and discussion in the emergency management and public health fields.

\section{References}

1. Committee on Crisis Standards of Care, Board on Health Sciences Policy, \& Institute of Medicine. Crisis Standards of Care: A Toolkit for Indicators and Triggers. Washington, DC USA: National Academies Press; 2013.

2. Hertelendy AJ, Ciottone GR, Mitchell CL, Gutberg J, Burkle FM. Crisis standards of care in a pandemic: navigating the ethical, clinical, psychological, and policy-making maelstrom. International Journal for Quality in Health Care. 2020.

3. National Academies of Sciences, Engineering, and Medicine. Crisis Standards of Care: Ten Years of Successes and Challenges - Proceedings of a Workshop. Washington, DC USA: The National Academies Press; 2020.

4. Romney D, Fox H, Carlson S, Bachmann D, O'Mathuna D, Kman N. Allocation of scarce resources in a pandemic: a systematic review of US state crisis standards of care documents. Disaster Med Public Health Prep. 2020. Epub ahead of print.

5. White DB, Lo B. A framework for rationing ventilators and critical care beds during the COVID-19 pandemic. JAMA. 2020;323(18):1773-1774.

6. Leider JP, DeBruin D, Reynolds N, Koch A, Seaberg J. Ethical guidance for disaster response, specifically around crisis standards of care: a systematic review. Am J Public Health. 2017;107(9):e1-e9.

7. Schultz CH, Annas GJ. Altering the standard of care in disasters - unnecessary and dangerous. Ann Emerg Med. 2012;59(3):191-195.

8. Margus C, Sarin RR, Molloy M, Ciottone GR. Crisis standards of care implementation at the state level in the United States. Prehosp Disaster Med. 2020. Epub ahead of print.

9. Health and Human Services. State Level Crisis Standards of Care. https://files asprtracie.hhs.gov/documents/4-9-20-state-level-csc-plans-guidance-policy.pdf. Accessed July 24, 2020.

10. Standards of Care Workgroup, CT Department of Public Health. Standards of Care: Providing Health Care During a Prolonged Public Health Emergency. https://portal. ct.gov/-/media/Departments-andAgencies/DPH/dph/legal/StandardsofCarefinalpdf. pdf?la=en. Accessed July 24, 2020.

11. Herbert K, Gray B. Hospitals in Hurricane Katrina: challenges facing custodial institutions in a disaster. J Health Care Poor Underserved. 2007;18(2):283-298.

12. Ajao A, Baccam P, Chamberlin M, et al. Assessing the capacity of the US health care system to use additional mechanical ventilators during a large-scale public health emergency. Disaster Med Public Health Prep. 2015;9(6):634-641.

13. Pandemic and All-Hazards Preparedness and Advancing Innovation Act (PAHPA) of 2019. 42 USC $247 d-3 c$.

14. Eckenwiler L. Ethics and the underpinnings of policy in biodefense and emergency preparedness. Cambridge Quarterly of Healthcare Ethics. 2005;14(3):306-315.

15. Crisis standards of care: a systems framework for catastrophic disaster response. Military Med. 2016;1717(8):719-721.

16. Zack N. Philosophy and Disaster. Homeland Security Affairs. 2006;2(1):5.

17. Courtney B. Five legal preparedness challenges for responding to future public health emergencies. J Law Med Ethics. 2011;39(1):60-64. 